ARTICLE

Clinical Study

\title{
Predictive values of colorectal cancer alarm symptoms in the general population: a nationwide cohort study
}

\author{
Sanne Rasmussen ${ }^{1}$, Peter Fentz Haastrup ${ }^{1}$, Kirubakaran Balasubramaniam¹, Sandra Elnegaard ${ }^{1}$, René dePont Christensen ${ }^{1}$, \\ Maria Munch Storsveen ${ }^{1}$, Jens Søndergaard ${ }^{1}$ and Dorte Ejg Jarbøl ${ }^{1}$
}

BACKGROUND: Alarm symptoms are used in many cancer referral guidelines. The objectives were to determine the 1-year predictive values (PVs) of colorectal cancer (CRC) alarm symptoms in the general population and to describe the proportion of alarm symptoms reported prior to diagnosis.

METHODS: A nationwide prospective cohort of 69,060 individuals $\geq 40$ years randomly selected from the Danish population was invited to complete a survey regarding symptoms and healthcare-seeking in 2012. Information on CRC diagnoses in a 12-month follow-up came from the Danish Cancer Registry. PVs and positive and negative likelihood ratios were calculated.

RESULTS: A total of 37,455 individuals participated (response rate 54.2\%). Sixty-four individuals were diagnosed with CRC. The single symptom with the highest positive PVs (PPV) and LR+ was rectal bleeding. PPVs were generally higher among individuals aged $\geq 75$ years and highest among those reporting at least one specific alarm symptom that led to a GP contact.

CONCLUSION: In general, the PPVs of CRC alarm symptoms are low and the NPVs high, especially in the youngest age groups. The $\mathrm{LR}+$ show a relative association with specific symptoms like rectal bleeding. Future campaigns on early diagnosis of CRC should focus on healthcare-seeking when experiencing rectal bleeding and target older people with the highest incidence.

British Journal of Cancer (2019) 120:595-600; https://doi.org/10.1038/s41416-019-0385-x

\section{BACKGROUND}

Colorectal cancer (CRC) causes substantial morbidity and mortality throughout the world and the highest incidence is seen in developed countries with a Western culture. ${ }^{1}$ The prognosis of CRC is highly dependent on the stage of disease at diagnosis. The 5 -year survival rate ranges from $90 \%$ for localised stage CRC to $10 \%$ for patients with distant metastases. ${ }^{2}$ To promote early diagnosis and improve survival rates, many countries have implemented cancer referral guidelines and fast track endoscopy for patients with alarm symptoms indicative of CRC. ${ }^{3,4}$ For CRC, alarm symptoms are specific symptoms such as rectal bleeding or changes in bowel patterns for individuals $\geq 40$ years. However, non-specific symptoms such as weight loss and tiredness could be important markers of malignant disease and, in general, almost half of cancer patients present non-specific symptoms prior to diagnosis. ${ }^{5}$ In Denmark, screening for CRC is offered to people in the age of $50-74$ years. However, only approximately $25 \%$ of all CRC are detected by screening. ${ }^{6}$ For the rest of the cases and in the group aged 75 years and older, symptoms will still have a significant role in the diagnostic process of CRC.

It has been demonstrated that both specific and non-specific symptoms of CRC are common in the general population and few consult their general practitioner (GP) when experiencing alarm symptoms of $\mathrm{CRC}^{7}$ Positive predictive values (PPVs) for alarm symptoms of CRC have mostly been investigated for persons consulting their GP with alarm symptoms and little is known about the negative predictive values (NPVs). ${ }^{8-10}$ As campaigns to increase public awareness of alarm symptoms and promote earlier presentation by the patients are progressively carried out worldwide, ${ }^{11}$ it is important to gather knowledge about the PVs of alarm symptoms in the general population.

The aims of this study were (1) to determine the 1-year PV of specific and non-specific alarm symptoms of CRC in the general population 40 years or above and (2) to describe the proportion of specific and non-specific alarm symptoms reported by patients prior to diagnosis of CRC.

\section{METHODS}

Study design and population

The study was designed as a nationwide cohort study based on questionnaires and national registries, imbedded in the Danish Symptom Cohort (DaSC). ${ }^{12}$ This particular study aimed to gather knowledge about the predictive values of specific and nonspecific alarm symptoms of CRC in the general population. Other studies have already reported predictive values of gynaecological cancer alarm symptoms ${ }^{13}$ and upper gastrointestinal cancer. ${ }^{14}$ Parts of the methods described below have therefore been previously described. ${ }^{7,12,15}$

From the Danish Civil Registration System (CRS), 100,000 adults aged 20 years or above were randomly selected and invited to participate in a survey. All Danish citizens are registered in the CRS with a unique personal identification number. Prior to the sampling procedure, individuals were excluded if they had

\footnotetext{
${ }^{1}$ Research Unit of General Practice, Department of Public Health, University of Southern Denmark, J. B. Winsløws Vej 9A, 5000 Odense C, Denmark
} Correspondence: Sanne Rasmussen (sarasmussen@health.sdu.dk)

Received: 13 June 2018 Revised: 7 January 2019 Accepted: 10 January 2019

Published online: 22 February 2019 


\begin{tabular}{l} 
Table 1. Specific and non-specific alarm symptom \\
cancer \\
\hline Specific alarm symptoms of colorectal cancer \\
Abdominal pain \\
Change in stool texture ${ }^{\mathrm{a}}$ \\
Change in stool frequency \\
Blood in stool/rectal bleeding \\
Non-specific alarm symptoms of colorectal cancer \\
Diarrhoea \\
Constipation \\
Abdominal bloating \\
Weight loss \\
Feeling unwell \\
Tiredness
\end{tabular}

anly experience of symptoms more than 1 month earlier was included

declared to the CRS that they did not want research-related inquiries. The individuals received a postal letter explaining the purpose of the study. The questionnaire was designed using the internet-based platform SurveyXact. ${ }^{16}$ A unique login for a secure webpage was included in the letter. This provided access to a comprehensive web-based questionnaire. To prevent exclusion of people with no access to the internet, participants were offered to complete the survey by telephone interview. When an invited subject was unable to respond due to severe illness or having moved abroad, family or relatives could decline the invitation on behalf of the invited person. The reason for not responding was then registered as illness or moved abroad.

\section{The questionnaire}

The methodological framework for developing, pilot testing and field testing the questionnaire is described in detail elsewhere. ${ }^{12}$ This paper addresses the specific and non-specific symptoms indicative of CRC. These symptoms were selected based on a review of literature, national and international cancer referral guidelines and descriptions of cancer pathways. ${ }^{3,4,17}$ In total, ten predefined symptoms reported by individuals aged 40 years or above form the base of this paper (Table 1). The four specific symptoms and the age limit were chosen as it is included in the Danish cancer referral guidelines (Supplementary Figure 1). The respondents were asked whether or not they had experienced one or more of the symptoms in the preceding 4 weeks. The respondents were additionally asked whether or not they had contacted their GP regarding the symptom. The wording of the question regarding symptom experience was: "Have you experienced any of the following sensations, symptoms or discomfort within the past 4 weeks?" with the option to select one or more of the predefined symptoms. With regard to GP contact, the question was worded: "Have you contacted your general practitioner concerning the symptom(s) you have experienced within the preceding four weeks, by appointment, telephone or email?" An item concerning when the symptom(s) occurred for the first time was also included. The response categories were: "less than one month ago", "1-3 months ago", "3-6 months ago" or "more than six months ago".

\section{Register data}

Information on CRC diagnoses in the respondent cohort aged 40 years or above was retrieved from the Danish Cancer Registry (DCR). The DCR contains personal and tumour characteristics for all incident cancer cases in Denmark including date of diagnosis and ICD-10 codes for lesions. ${ }^{18}$ Only cases diagnosed in a 12month period after the completion of the questionnaire were
Table 2. ICD-10 codes used for incident cancer cases

\begin{tabular}{ll}
\hline ICD-10 diagnose code & Name \\
\hline DC18 & Malignant neoplasm of colon \\
DC180 - DC189, excl. & Malignant neoplasm in various parts of \\
DC189X & colon, excluding relapse \\
DC20 + DC209, excl. & Malignant neoplasm of rectum, excluding \\
DC209X & relapse \\
\hline
\end{tabular}

included. Furthermore, the cases were excluded if the individual had been diagnosed with the same ICD-10 code in a time period covering 5 years prior to the completion of the questionnaire. The ICD-10 codes used in this study are listed in Table 2.

Statistical analyses

PPVs were calculated by dividing the number of symptomatic individuals diagnosed with CRC by the total number of symptomatic individuals in each category. NPVs were calculated by dividing the number of asymptomatic respondents not subsequently diagnosed with CRC by the total number of asymptomatic respondents. The PVs are presented as percentages. PPVs and NPVs for CRC were calculated for each category. Moreover, we calculated the positive likelihood ratios $(\mathrm{LR}+)$ and negative likelihood ratios ( $L R-$ ) as a relative measure of the association between symptom experience and CRC. The PVs and LRs for CRC were calculated for each of the four specific alarm symptoms of CRC and for each of the six non-specific alarm symptoms for the total population (aged $\geq 40$ years) and separately for two age groups $40-74$ and $\geq 75$ years. For change in bowel patterns (stool texture and frequency), only experience of symptoms for the first time more than 1 month earlier was included. Moreover, the PVs and LRs were calculated for: (1) at least one of the ten alarm symptoms, (2) at least one of the specific alarm symptoms, (3) at least one of the non-specific alarm symptoms, (4) GP contact with at least one of the ten alarm symptoms and (5) GP contact with at least one specific alarm symptom. The PVs and LRs in these five groups were calculated for both the entire study population of respondents aged 40 years or above as well as for subgroups of individuals under and above 75 years of age. The proportions of specific and non-specific alarm symptoms of CRC reported by individuals aged 40 years or above diagnosed with CRC are presented.

All statistical tests used a significance level of $P<0.05$. Data analyses were conducted using STATA statistical software 13.1 (StataCorp, College Station, TX, USA). In concordance with the Danish data protection act only summary tables with four or more individuals in each count are reported.

\section{RESULTS}

Of the 100,000 randomly selected subjects, 4474 (4.7\%) were not eligible because they had either died, could not be reached due to unknown address, were suffering from severe illnesses, had language problems or had moved abroad. A total of 95,253 subjects were eligible for the study, of these 69,060 were aged 40 years or above and 37,455 completed the questionnaire, yielding an overall response rate of $54.2 \%$ (Fig. 1). The mean age of the respondents in this age group was 58.4 years (95\% confidence interval (Cl): $58.3-58.6)$ compared to 60.8 years (95\% Cl: 60.6-61.0) for non-respondents. Slightly more respondents were women (52.7\%) compared to non-respondents $(50.2 \%)$. The respondents were more often women married/co-habiting and had a higher income and educational level and were more often affiliated to the labour market (Table 5).

In total, 64 individuals (0.17\%) were diagnosed with CRC 1 year after completing the questionnaire. Of these, 41 (64.1\%) were 
Sampling frame: 100,000 randomly selected Danis people aged 20 years or more

men $=48,910(48.9 \%)$, women $=51,090(51.1 \%)$

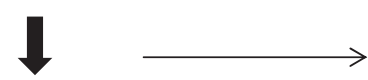

Eligible for the study: 95,253 (95.3\%)

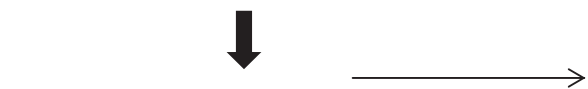

Respondents: 49,706 (52.2\%)

men $=23,240(46.8 \%)$, women $=26,466(53.2 \%)$

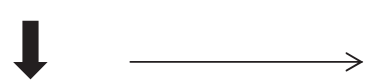

Respondents aged $\geq 40$ : $37,455(54.2 \%)$

men $=17,701(47.3 \%)$, women $=19,754(52.7 \%)$
Excluded: 4747 (4.7\%)

Dead: 315

Addresses unknown: 961

Suffering from severe illness (including

dementia): 1972

Language problems: 885

Moved abroad: 614

\section{Non-respondents aged $\geq 40: 31,605$}

$\operatorname{men}=15,742(49.8 \%)$, women $=15,863(50.2 \%)$

Fig. 1 Study cohort

Table 3. Number of respondents $(n, \%)$, cases of colorectal cancers, numbers $(n, \%)$ (total numbers $n=64)$, PPVs (\%) with $95 \% \mathrm{Cl}$ and LR+ and LRwith regard to symptom type $(n=37,455)$

\begin{tabular}{|c|c|c|c|c|c|c|}
\hline & Respondents, $n$ (\%) & Cancer cases, $n$ (\%) & PPV $(95 \% \mathrm{Cl})$ & $\mathrm{LR}+(95 \% \mathrm{CI})$ & NPV $(95 \% \mathrm{Cl})$ & $\mathrm{LR}-(95 \% \mathrm{Cl})$ \\
\hline Abdominal pain & $6223(16.6)$ & $17(26.6 \%)$ & $0.3(0.2 ; 0.4)$ & $1.6(1.1 ; 2.4)$ & $99.8(99.8 ; 99.9)$ & $0.9(0.8 ; 1.0)$ \\
\hline Change in stool texture ${ }^{a}$ & $5407(14.4)$ & $6(9.4 \%)$ & $0.2(0.1 ; 0.4)$ & $1.0(0.5 ; 2.2)$ & $99.8(99.8 ; 99.9)$ & $1.0(0.9 ; 1.1)$ \\
\hline Blood in stool/rectal bleeding & $1378(3.7)$ & $8(12.5 \%)$ & $0.6(0.3 ; 1.1)$ & $3.4(1.8 ; 6.5)$ & $99.8(99.8 ; 99.9)$ & $0.9(0.8 ; 1.0)$ \\
\hline Constipation & $4945(13.2)$ & 7 (10.9\%) & $0.1(0.1 ; 0.3)$ & $0.8(0.4 ; 1.7)$ & $99.8(99.8 ; 99.9)$ & $1.0(0.9 ; 1.1)$ \\
\hline Abdominal bloating & $9775(26.1)$ & $20(31.3 \%)$ & $0.2(0.1 ; 0.3)$ & $1.2(0.8 ; 1.7)$ & $99.8(99.8 ; 99.9)$ & $0.9(0.8 ; 1.1)$ \\
\hline Feeling unwell & $4301(11.5)$ & $6(9.4 \%)$ & $0.1(0.1 ; 0.3)$ & $0.8(0.4 ; 1.7)$ & $99.8(99.8 ; 99.9)$ & $1.0(0.9 ; 1.1)$ \\
\hline Tiredness & $16,282(43.5)$ & $26(40.6 \%)$ & $0.2(0.1 ; 0.2)$ & $0.9(0.7 ; 1.3)$ & $99.8(99.8 ; 99.9)$ & $1.1(0.9 ; 1.3)$ \\
\hline
\end{tabular}

males, and 23 (35.9\%) were women. The mean age of the individuals diagnosed with CRC was 69.7 years (95\% Cl: 67.3-72.1).

Due to too few observations, only PVs for nine of the ten predefined symptoms are reported (i.e. PVs for unintended weight loss is not reported). The PPVs of the four specific alarm symptoms for CRC (abdominal pain, change in stool texture, change in stool frequency, blood in stool/rectal bleeding) ranged between $0.2 \%$ (95\% Cl: $0.1-0.4)$ (change in stool texture) and $0.6 \%(95 \% \mathrm{Cl}$ : 0.3-1.1) (rectal bleeding) (Table 3). The PPVs of the five nonspecific alarm symptoms for CRC (diarrhoea, constipation, abdominal bloating, feeling unwell, tiredness) ranged between $0.1 \%$ (95\% Cl: $0.1-0.3$ ) (constipation and feeling unwell) and $0.3 \%$ (95\% Cl: 0.1-0.5) (diarrhoea) (Table 3). The NPVs were 99.8 for all the specific and non-specific alarm symptoms (Table 3 ).

The PVs and LRs for CRC among individuals under and above 75 years are given in Table 4 and demonstrate the difference between age groups. Generally, the PPVs were lower and the NPVs higher in the group younger than 75 years compared to those aged 75 years and above. For the individuals aged 75 years or above who had reported at least one specific alarm symptom, a PPV of $1.0 \%$ (95\% Cl: $0.4-2.0)$ and an NPV of $99.5 \%(95 \% \mathrm{Cl}$ : 99.1-99.7) for CRC was estimated. Individuals aged 75 years or above reporting at least one of the specific alarm symptoms that lead to a GP contact had a PPV of $1.9 \%$ and LR+ of 3.0 for being diagnosed with CRC and the NPVs and LR- for this group was 99.5\% (95\% Cl: $99.2-99.7)$ and $0.8 \%(95 \% \mathrm{Cl}: 0.6-1.0)$ respectively (Table 4).

Of the individuals diagnosed with CRC, $43.8 \%$ had experienced at least one of the four specific alarm symptoms. Abdominal pain was the most common specific alarm symptom reported by $26.6 \%$ of the 64 individuals diagnosed with CRC. In total, $40.6 \%$ had reported tiredness, this being the most common non-specific symptom. Of the individuals diagnosed with CRC, $65.6 \%$ had experienced at least one of the specific and non-specific alarm symptoms. 
Predictive values of colorectal cancer alarm symptoms in the general...

S Rasmussen et al.

Table 4. Number of respondents ( $n, \%)$, cases of colorectal cancers, numbers $(n, \%)$, PPVs (\%) and NPVs (\%) with $95 \% \mathrm{Cl}$ and LR+ and LR- with $95 \%$ $\mathrm{Cl}$ with regard to specific and non-specific cancer alarm symptoms and stratified on age group (under and above 75 years of age)

\begin{tabular}{|c|c|c|c|c|c|c|}
\hline & Respondents, $n$ (\%) & Cancer cases, $n(\%)$ & & & & \\
\hline Total & $37,455(100 \%)$ & $64(100 \%)$ & & & & \\
\hline$<75$ years & $34,323(91.6 \%)$ & $44(68.8 \%)$ & & & & \\
\hline \multirow[t]{2}{*}{$\geq 75$ years } & $3132(8.4 \%)$ & $20(31.2 \%)$ & & & & \\
\hline & Respondents, $n$ (\%) & Cancer cases, $n$ (\%) & PPV $(95 \% \mathrm{Cl})$ & $\mathrm{LR}+(95 \% \mathrm{Cl})$ & NPV $(95 \% \mathrm{Cl})$ & $\mathrm{LR}-(95 \% \mathrm{Cl})$ \\
\hline \multicolumn{7}{|c|}{ At least one alarm symptom } \\
\hline Total & $23,499(62.7 \%)$ & $42(65.6 \%)$ & $0.2(0.1 ; 0.2)$ & $1.0(0.9 ; 1.2)$ & $99.8(99.8 ; 99.9)$ & $0.9(0.7 ; 1.3)$ \\
\hline$<75$ years & $21,766(92.6 \%)$ & $30(71.4 \%)$ & $0.1(0.1 ; 0.2)$ & $1.1(0.9 ; 1.3)$ & $99.9(99.8 ; 99.9)$ & $0.9(0.6 ; 1.3)$ \\
\hline$\geq 75$ years & $1733(7.4 \%)$ & $12(28.6 \%)$ & $0.7(0.4 ; 1.2)$ & $1.1(0.8 ; 1.6)$ & $99.4(98.9 ; 99.8)$ & $0.9(0.5 ; 1.5)$ \\
\hline \multicolumn{7}{|c|}{ At least one specific alarm symptom } \\
\hline Total & 9925 (26.5\%) & $28(43.8 \%)$ & $0.3(0.2 ; 0.4)$ & $1.7(1.3 ; 2.2)$ & $99.9(99.8 ; 99.9)$ & $0.8(0.6 ; 0.9)$ \\
\hline$<75$ years & $9206(92.8 \%)$ & $21(75.0 \%)$ & $0.2(0.1 ; 0.3)$ & $1.8(1.3 ; 2.4)$ & $99.9(99.9 ; 99.9)$ & $0.7(0.5 ; 0.9)$ \\
\hline$\geq 75$ years & 719 (7.2\%) & 7 (25.0\%) & $1.0(0.4 ; 2.0)$ & $1.5(0.8 ; 2.8)$ & $99.5(99.1 ; 99.7)$ & $0.8(0.6 ; 1.2)$ \\
\hline \multicolumn{7}{|c|}{$\begin{array}{l}\text { At least one non-specific alarm } \\
\text { symptom }\end{array}$} \\
\hline Total & $22,343(62.3 \%)$ & $40(62.5 \%)$ & $0.2(0.1 ; 0.2)$ & $1.0(0.9 ; 1.3)$ & $99.8(99.8 ; 99.9)$ & $0.9(0.7 ; 1.3)$ \\
\hline$<75$ years & $20,711(92.7 \%)$ & 29 (72.5\%) & $0.1(0.1 ; 0.2)$ & $1.1(0.9 ; 1.4)$ & $99.9(99.8 ; 99.9)$ & $0.9(0.6 ; 1.3)$ \\
\hline$\geq 75$ years & 1632 (7.3\%) & 11 (27.5\%) & $0.7(0.3 ; 1.2)$ & $1.1(0.7 ; 1.6)$ & $99.4(98.9 ; 99.7)$ & $0.9(0.6 ; 1.5)$ \\
\hline \multicolumn{7}{|c|}{$\begin{array}{l}\text { Symptom experience and GP } \\
\text { contact with at least one alarm } \\
\text { symptom }\end{array}$} \\
\hline Total & $6523(17.4 \%)$ & 20 (31.3\%) & $0.3(0.2 ; 0.5)$ & $1.8(1.2 ; 2.6)$ & $99.9(99.8 ; 99.9)$ & $0.8(0.7 ; 1.0)$ \\
\hline$<75$ years & 5770 (88.5\%) & $13(65.0 \%)$ & $0.2(0.1 ; 0.4)$ & $1.8(1.1 ; 2.8)$ & $99.9(99.8 ; 99.9)$ & $0.8(0.7 ; 1.0)$ \\
\hline$\geq 75$ years & 753 (11.5\%) & 7 (35.0\%) & $0.9(0.4 ; 1.9)$ & $1.5(0.8 ; 2.7)$ & $99.5(99.1 ; 99.7)$ & $0.9(0.6 ; 1.2)$ \\
\hline \multicolumn{7}{|c|}{$\begin{array}{l}\text { Symptom experience and GP } \\
\text { contact with at least one specific } \\
\text { alarm symptom }\end{array}$} \\
\hline$<$ Total & 2910 (7.8\%) & $14(21.9 \%)$ & $0.5(0.3 ; 0.8)$ & $2.8(1.8 ; 4.5)$ & $99.9(99.8 ; 99.9)$ & $0.8(0.7 ; 1.0)$ \\
\hline$<75$ years & 2596 (89.2\%) & $8(57.1 \%)$ & $0.3(0.1 ; 0.6)$ & $2.4(1.3 ; 4.5)$ & $99.9(99.8 ; 99.9)$ & $0.9(0.8 ; 1.0)$ \\
\hline$\geq 75$ years & 314 (10.8\%) & 6 (42.9\%) & $1.9(0.7 ; 4.1)$ & $3.0(1.5 ; 6.0)$ & $99.5(99.2 ; 99.7)$ & $0.8(0.6 ; 1.0)$ \\
\hline
\end{tabular}

$P P V$ positive predictive values, $N P V$ negative predictive values, $L R+$ positive likelihood ratios, $L R$ - negative likelihood ratios, $C l$ confidence interval

\section{DISCUSSION}

Main findings

In this study, we investigated the PPVs, NPVs, LR+ and LR- of specific and non-specific alarm symptoms for CRC in the general population. The overall findings are that although the PPVs are low, the $\mathrm{LR}+\mathrm{s}$ show a relative association with symptoms (e.g. LR+ 3.4 for rectal bleeding), and although the NPVs were high, the LRestimates were too uncertain to conclude that individuals without symptoms are in no risk of CRC.

In general, the PPVs were higher among individuals aged 75 years and above compared to those aged $40-74$ years. The NPVs were highest in the youngest age groups. The highest PPV was found among individuals aged 75 years and above reporting at least one of the specific alarm symptoms that led to a GP contact. The $L R+$ was substantially higher for individuals experiencing the specific alarm symptoms (LR+ $3.4 \%$ for rectal bleeding) when compared to the non-specific alarm symptoms (LR+ $1.2 \%$ for abdominal bloating). The lowest LR - was found for individuals aged $40-74$ years reporting at least one specific alarm symptom.

Strengths and limitations

The major strength of this study is the prospective cohort design following a large cohort of the general population, which gives the opportunity to retrieve information about symptom experiences prior to diagnosis. With this study design we minimised the risk of recall bias that is often seen in studies regarding cancer patients' symptoms prior to diagnosis. The use of register-based diagnoses rather than asking the respondents further reduced the risk of recall bias. The DCR was used to identify cases of cancer. This registry is based on mandatory data from several sources and is a valid source of information on diagnoses. ${ }^{18}$

A general weakness of questionnaire-based studies is that respondents may not interpret the questions and categories of answers as intended. Prior to the survey, we conducted several rounds of pilot testing and field testing to reduce this possibility. ${ }^{12}$ Based on the results of the pilot testing, it seems reasonable to assume that the respondents understood the questions as intended.

This study reflects self-reported experience of symptoms within the preceding 4 weeks and subsequent contacts with a GP. Although we asked for symptom experiences and GP contacts within a short time period, some memory decay cannot be ruled out. Another limitation to keep in mind is the fact that willingness to respond to a questionnaire regarding symptom experiences may be associated with the presence of symptoms. It has been demonstrated that individuals with many or severe symptoms and vulnerable personality may be more prone to participate in a survey about symptoms. ${ }^{19,20}$

The age distribution of the cohort is skewed in the older age groups with regard to respondents and non-respondents (Table 5). However, as we do not know the symptom experience of the nonrespondents we cannot know how this difference affects our results. 
Table 5. Socio-demographic characteristics for the cohort of 69,060 individuals $\geq 40$ years

\begin{tabular}{|c|c|c|c|}
\hline & Total, N (\%) & $\begin{array}{l}\text { Respondents, } \\
n(\%)\end{array}$ & $\begin{array}{l}\text { Non- } \\
\text { respondents, } \\
n(\%)\end{array}$ \\
\hline Total & $69,060(100.0 \%)$ & $37,455(100.0 \%)$ & $31,605(100.0 \%)$ \\
\hline \multicolumn{4}{|l|}{ Sex } \\
\hline Male & $33,443(48.4 \%)$ & $17,701(47.3 \%)$ & $15,742(49.8 \%)$ \\
\hline Female & 35,617 (51.6\%) & $19,754(52.7 \%)$ & $15,863(50.2 \%)$ \\
\hline \multicolumn{4}{|l|}{ Age groups } \\
\hline $40-59$ & 36,187 (52.4\%) & 20,305 (54.2\%) & $15,882(50.3 \%)$ \\
\hline $60-79$ & $27,745(40.2 \%)$ & $15,748(42.0 \%)$ & $11,997(38.0 \%)$ \\
\hline $80+$ & $5128(7.4 \%)$ & 1402 (3.7\%) & 3726 (11.8\%) \\
\hline \multicolumn{4}{|l|}{ Marital status } \\
\hline Single & $21,191(30.7 \%)$ & $8423(22.5 \%)$ & $12,768(40.5 \%)$ \\
\hline $\begin{array}{l}\text { Married/ } \\
\text { cohabiting }\end{array}$ & $47,801(69.3 \%)$ & $29,008(77.5 \%)$ & $18,793(59.5 \%)$ \\
\hline \multicolumn{4}{|l|}{ Educational level } \\
\hline Low $(<10$ years $)$ & 19,792 (29.5\%) & 8002 (21.7\%) & $11,790(38.9 \%)$ \\
\hline $\begin{array}{l}\text { Middle (10-12 } \\
\text { years) }\end{array}$ & $28,959(43.1 \%)$ & $16,557(45.0 \%)$ & $12,402(40.9 \%)$ \\
\hline High (>12 years) & $18,386(27.4 \%)$ & $12,263(33.3 \%)$ & $6123(20.2 \%)$ \\
\hline \multicolumn{4}{|c|}{ Labour market affiliation } \\
\hline Working & $37,603(54.5 \%)$ & $22,930(61.2 \%)$ & $14,673(46.5 \%)$ \\
\hline $\begin{array}{l}\text { Retirement } \\
\text { pension }\end{array}$ & $23,193(33.6 \%)$ & $11,294(30.2 \%)$ & $11,899(37.7 \%)$ \\
\hline $\begin{array}{l}\text { Out of } \\
\text { workforce }\end{array}$ & $8228(11.9 \%)$ & $3222(8.6 \%)$ & $5006(15.9 \%)$ \\
\hline \multicolumn{4}{|c|}{ Equivalence weighted disposable income } \\
\hline $\begin{array}{l}\text { Low (1st } \\
\text { quartile) }\end{array}$ & $13,598(19.7 \%)$ & $4498(12.0 \%)$ & $9100(28.8 \%)$ \\
\hline $\begin{array}{l}\text { Middle (2nd and } \\
\text { 3rd quartile) }\end{array}$ & $35,122(50.9 \%)$ & $19,309(51.6 \%)$ & $15,813(50.1 \%)$ \\
\hline $\begin{array}{l}\text { High (4th } \\
\text { quartile) }\end{array}$ & $20,272(29.4 \%)$ & $13,624(36.4 \%)$ & $6648(21.1 \%)$ \\
\hline \multicolumn{4}{|l|}{ Ethnicity } \\
\hline Danish & $64,418(93.4 \%)$ & $35,609(95.1 \%)$ & $28,809(91.3 \%)$ \\
\hline $\begin{array}{l}\text { Immigrants and } \\
\text { descendants of } \\
\text { immigrants }\end{array}$ & $4574(6.6 \%)$ & $1822(4.9 \%)$ & $2752(8.7 \%)$ \\
\hline
\end{tabular}

We investigated whether non-respondents had a higher number of CRC and found slightly more cases of CRC among non-respondents in the age group $\geq 40$ years ( 64 cases among the $37,455(0.17 \%)$ respondents compared to 72 cases among the $31,605$ non-respondents $(0.23 \%))$. The differences in the number of CRCs in the two groups might be affected by a number of factors. Firstly, the non-responders were slightly older than the respondents. Since the incidence of CRC increases with age, this might be an associated factor. Older age might be associated with a higher degree of comorbidity and therefore lower capacity to participate in the survey. Secondly, it could be due to socioeconomic factors. A Danish study from 2008 found that higher incidences of CRC were associated with social disadvantages predominantly amongst men, specifically related to co-habiting status, housing tenure, dwelling size and affiliation to the labour market. $^{21}$ The non-respondents in our study had lower socioeconomic status compared to respondents. A third possible associated factor could be that people who take their symptoms less seriously are more likely to have $\mathrm{CRC}^{22}$ As the nonrespondents did not wish to participate in the survey on symptoms and healthcare-seeking, one could hypothesise that they were less likely to take symptoms seriously.

The limited number of cases of CRC might affect the reliability of the results. Due to the limited number of cases of CRC in the follow-up period, we did not have sufficient power to evaluate the PVs of combinations of alarm symptoms. It is plausible that experiencing more than one alarm symptom increases the risk of malignancy. ${ }^{23}$ From previous studies we know that experiencing multiple symptoms increases the probability of seeking medical attention. $^{15}$ Therefore, the non-specific symptoms of CRC might play an important role in the diagnostic pathway.

Comparison with previous literature

To our knowledge, this is the only population-based study estimating PPVs and NPVs of alarm symptoms of CRC with corresponding LR+ and LR-. A literature study by Fijten et al., ${ }^{24}$ which includes nine population-based studies, estimated the PPV of rectal bleeding to be 1 in 1000. A relatively new systematic review investigating the diagnostic value of rectal bleeding found PPVs ranging from 0.01 to $0.21 \% .^{25}$ However, this review was comprised of studies from various settings and all the populationbased studies targeted screening of CRC.

Several studies have investigated the diagnostic values of alarm symptoms of CRC in primary care ${ }^{8,23,26}$ and found PVs highest for rectal bleeding and anaemia. This is in line with the present results where the single symptom with highest PPV was rectal bleeding. The PPVs in the studies from general practice were substantially higher. A review by Astin et al. ${ }^{23}$ found that PPVs for rectal bleeding as single symptom varied between 2.2 and $15.8 \%$. The findings in the present study support this suggestion, as alarm symptoms presented to the GP had a higher PPV compared to alarm symptoms not reported to the GP. This indicates that deciding to consult the GP with a symptom increases the likelihood of the symptom being caused by a disease.

In a previous study, we have demonstrated that no more than $33.8 \%$ of the individuals in the general population who experienced rectal bleeding consulted their GP. ${ }^{7}$ This in line with the findings from Crosland and Jones ${ }^{27}$ who found that $41 \%$ of people from the general population had consulted their GP when experiencing rectal bleeding. These results combined with results from the present study have clear implications for modelling the impact and cost-effectiveness for public awareness campaigns. Unfortunately, awareness campaigns have not yet shown to improve survival. ${ }^{28}$ Although screening has been implemented in some countries, most CRC patients are still to be found based on symptoms. Instead of general awareness campaigns, targeted education of older persons, who have the highest incidence, might have an effect on healthcare-seeking and ultimately survival of CRC. It is important that we communicate the importance of healthcare-seeking with the defined alarm symptoms and the fact that low risk is not no risk. Informing patients referred for fast track investigation of CRC about the modest risk of actually having CRC could possibly reduce the anxiety related to investigation for suspected cancer. ${ }^{29}$

\section{CONCLUSIONS}

This study supports our hypothesis that PPVs of alarm symptoms of CRC experienced in an unselected general population were lower than PPVs of symptoms presented in hospitals or general practices. The single symptom with highest PPV was rectal bleeding. The fact that rectal bleeding as an initial symptom is associated with a less advanced stage of CRC and increased survival rate ${ }^{9}$ supports the idea that future campaigns aiming to promote early diagnosis should focus on increasing healthcareseeking when experiencing rectal bleeding. Individuals aged 
75 years and above who reported having contacted the GP with the alarm symptoms had the highest PPV. This finding gives reason to further explore the process of people's decision to seek healthcare and to target education of older persons, who have the highest incidence of CRC.

The PPVs for the alarm symptoms were low and the NPVs were high. Experiences of specific and non-specific alarm symptoms are frequent. This means that despite requiring further investigation, most patients with an alarm symptom of CRC do not have CRC.

\section{ACKNOWLEDGEMENTS}

The DaSC survey was conducted in collaboration between the Research Unit for General Practice, University of Southern Denmark and the Research Centre for Cancer Diagnosis in Primary Care, Aarhus University. We would like to thank Wade Thompson for proofreading the manuscript. This study is financially supported by grants from the Region of Southern Denmark. The funding body had no influence on the design, analysis, interpretation or writing the manuscript.

\section{AUTHOR CONTRIBUTIONS}

S.R., K.B., S.E., J.S. and D.E.J. participated in the design of the study. S.R., K.B., S.E. and D.E.J. participated in the logistics concerning the survey and collected the data. S.R., K.B., M.M.S. and R.D.C. analysed the data. P.F.H., S.R. and D.E.J. interpreted the data and drafted the first version of the manuscript. All authors have read and approved the final manuscript.

\section{ADDITIONAL INFORMATION}

Supplementary information is available for this paper at https://doi.org/10.1038/ s41416-019-0385-x.

Competing interests: The authors declare no competing interests.

Data availability: The datasets generated and analysed during the current study are not publicly available due to the data protection regulations of the Danish Data Protection, Statistics Denmark and the Danish Health and Medicines Authority. Access to data is strictly limited to the researchers who have obtained permission for data processing. This permission was granted to the Research Unit of General Practice, Department of Public Health, University of Southern Denmark.

Ethics approval and consent to participate: The Regional Scientific Ethics Committee for Southern Denmark evaluated the project and concluded that the project was not notifiable and could be implemented without the permission from The Regional Scientific Ethical Committee for Southern Denmark according to Danish law. The Scientific Ethics Committee's evaluation comprised all aspects of the project including the data collection. Answering the questionnaire was completely voluntary and unpaid. All respondents consented to transmission of information about diagnoses from the Danish national health registries. The participants in the study were clearly informed that there would be no clinical follow-up and that they should contact their own GP in case of concern or worry. The project has been approved by the Danish Data Protection Agency (journal number 2011-41-6651).

Consent for publication: When answering the questionnaire all respondents gave consent to publication of data.

Note: This work is published under the standard license to publish agreement. After 12 months the work will become freely available and the license terms will switch to a Creative Commons Attribution 4.0 International (CC BY 4.0).

Publisher's note: Springer Nature remains neutral with regard to jurisdictional claims in published maps and institutional affiliations.

\section{REFERENCES}

1. Haggar, F. A. \& Boushey, R. P. Colorectal cancer epidemiology: incidence, mortality, survival, and risk factors. Clin. Colon Rectal Surg. 22, 191-197 (2009).

2. Jemal, A. et al. Annual report to the nation on the status of cancer, 1975-2001, with a special feature regarding survival. Cancer 101, 3-27 (2004).
3. National Institute for Health and Clinical Excellence. Referral Guidelines for Suspected Cancer (NICE, London, 2005).

4. The Danish Health and Medicines Authority. Pakkeforløb for kræft $i$ tyk- og endetarm [Cancer Package for Colorectal Cancer] (Danish Health and Medicines Authority, Copenhagen, 2012).

5. Nielsen, T. N., Hansen, R. P. \& Vedsted, P. Symptom presentation in cancer patients in general practice. Ugeskr. Laege. 172, 2827-2831 (2010).

6. Hamilton, W. Five misconceptions in cancer diagnosis. Br. J. Gen. Pract. 59, 441-445 (2009). 7; discussion 6.

7. Rasmussen, S. et al. Specific and non-specific symptoms of colorectal cancer and contact to general practice. Fam. Pract. 32, 387-394 (2015).

8. Jones, R., Latinovic, R., Charlton, J. \& Gulliford, M. C. Alarm symptoms in early diagnosis of cancer in primary care: cohort study using General Practice Research Database. BMJ 334, 1040 (2007).

9. Stapley, S., Peters, T. J., Sharp, D. \& Hamilton, W. The mortality of colorectal cancer in relation to the initial symptom at presentation to primary care and to the duration of symptoms: a cohort study using medical records. Br. J. Cancer $\mathbf{9 5}$, 1321-1325 (2006)

10. Hamilton, W. The CAPER studies: five case-control studies aimed at identifying and quantifying the risk of cancer in symptomatic primary care patients. Br. J. Cancer 101(Suppl. 2), S80-S86 (2009).

11. Whyte, S. \& Harnan, S. Effectiveness and cost-effectiveness of an awareness campaign for colorectal cancer: a mathematical modeling study. Cancer Causes Control 25, 647-658 (2014).

12. Rasmussen, S. et al. The Danish Symptom Cohort: questionnaire and feasibility in the nationwide study on symptom experience and healthcare-seeking among 100000 individuals. Int. J. Fam. Med. 2014, 187280 (2014).

13. Balasubramaniam, K., Ravn, P., Christensen, R. D., Søndergaard, J. \& Jarbøl, D. Predictive values of gynaecological cancer alarm symptoms in a general population. Eur. J. Gynaecol. Oncol. 39, 543-547 (2018).

14. Rasmussen, $\mathrm{S}$. et al. Predictive values of upper gastrointestinal cancer alarm symptoms in the general population: a nationwide cohort study. BMC Cancer 18, 440 (2018).

15. Elnegaard, S. et al. Self-reported symptoms and healthcare seeking in the general population-exploring "The Symptom Iceberg". BMC Public Health 15, 685 (2015).

16. Rambøll Management Consulting. SurveyXact. https://www.surveyxact.dk/ 2012.

17. The Danish National Board of Health. Pakkeforløb for kræft i spiserør, mavesæk og mavemund [Cancer Package for Eosophageal, Stomach and Cardia Cancer] (Danish Health and Medicines Authority, Copenhagen, 2012).

18. Gjerstorff, M. L. The Danish Cancer Registry. Scand. J. Public Health 39(Suppl.), 42-45 (2011).

19. Nakash, R. A., Hutton, J. L., Lamb, S. E., Gates, S. \& Fisher, J. Response and nonresponse to postal questionnaire follow-up in a clinical trial-a qualitative study of the patient's perspective. J. Eval. Clin. Pract. 14, 226-235 (2008).

20. Galea, S. \& Tracy, M. Participation rates in epidemiologic studies. Ann. Epidemiol. 17, 643-653 (2007).

21. Egeberg, R., Halkjaer, J., Rottmann, N., Hansen, L. \& Holten, I. Social inequality and incidence of and survival from cancers of the colon and rectum in a population-based study in Denmark, 1994-2003. Eur. J. Cancer 44, 1978-1988 (2008).

22. Adelstein, B. A., Macaskill, P., Turner, R. M. \& Irwig, L. Patients who take their symptoms less seriously are more likely to have colorectal cancer. BMC Gastroenterol. 12, 130 (2012).

23. Astin, M., Griffin, T., Neal, R. D., Rose, P. \& Hamilton, W. The diagnostic value of symptoms for colorectal cancer in primary care: a systematic review. Br. J. Gen. Pract. 61, e231-e243 (2011).

24. Fijten, G. H., Blijham, G. H. \& Knottnerus, J. A. Occurrence and clinical significance of overt blood loss per rectum in the general population and in medical practice. Br. J. Gen. Pract. 44, 320-325 (1994).

25. Tong, G. X. et al. Diagnostic value of rectal bleeding in predicting colorectal cancer: a systematic review. Asian Pac. J. Cancer Prev. 15, 1015-1021 (2014).

26. Ewing, M., Naredi, P., Zhang, C. \& Mansson, J. Identification of patients with nonmetastatic colorectal cancer in primary care: a case-control study. Br. J. Gen. Pract. 66, e880-e886 (2016).

27. Crosland, A. \& Jones, R. Rectal bleeding: prevalence and consultation behaviour. BMJ 311, 486-488 (1995).

28. Khong, T. L., Naik, K., Sivakumar, R. \& Shah, S. Impact of the United Kingdom national bowel cancer awareness campaigns 2012 on colorectal cancer services and patient survival. Colorectal Dis. 17, 1055-1061 (2015).

29. Moseholm, E. et al. Health-related quality of life, anxiety and depression in the diagnostic phase of suspected cancer, and the influence of diagnosis. Health Qual. Life Outcomes 14, 80 (2016). 